\title{
Distinct roles of Hoxa2 and Krox20 in the development of rhythmic neural networks controlling inspiratory depth, respiratory frequency, and jaw opening
}

\author{
Fabrice Chatonnet ${ }^{1,2}$, Ludovic J Wrobel ${ }^{1}$, Valérie Mézières ${ }^{1}$, \\ Massimo Pasqualetti ${ }^{3,4}$, Sébastien Ducret ${ }^{3}$, Emmanuel Taillebourg, 5 , \\ Patrick Charnay ${ }^{5}$, Filippo M Rijli ${ }^{3}$ and Jean Champagnat*1
}

\begin{abstract}
Address: ${ }^{1 N G I, ~ U P R ~ 2216, ~ I n s t i t u t ~ d e ~ N e u r o b i o l o g i e ~ A l f r e d ~ F e s s a r d ~ I F R 2218, ~ C e n t r e ~ N a t i o n a l ~ d e ~ l a ~ R e c h e r c h e ~ S c i e n t i f i q u e, ~ F-91198 ~ G i f ~ s u r ~ Y v e t t e ~}$ Cedex, France, '2IGFL UMR 5242 CNRS/INRA/UCB/École Normale Supérieure de Lyon, allée d'Italie, 69364 Lyon Cedex 07, France, ${ }^{3}$ IGBMC, UMR 7104, CNRS/INSERM/ULP/Collège de France, CU de Strasbourg, F-67404 Illkirch Cedex, France, ${ }^{4}$ Laboratori di Biologia Cellulare e dello Sviluppo, Università di Pisa, Via G Carducci, Pisa, Italy, ${ }^{5}$ INSERM, U 784, Ecole Normale Supérieure, rue d'Ulm, 75230 Paris Cedex 05, France and ${ }^{6} \mathrm{CEA}$, Laboratoire de Biochimie et Biophysique des Systèmes Intégrés, 38054 Grenoble, France

Email: Fabrice Chatonnet - Fabrice.Chatonnet@ens-lyon.org; Ludovic J Wrobel - Ludovic.Wrobel@iaf.cnrs-gif.fr; Valérie Mézières - Valerie.mezieres@iaf.cnrs-gif.fr; Massimo Pasqualetti - m.pasqualetti@dfb.unipi.it;

Sébastien Ducret - Sebastien.Ducret@igbmc.u-strasbg.fr; Emmanuel Taillebourg - emmanuel.taillebourg@cea.fr;

Patrick Charnay - charnay@biologie.ens.fr; Filippo M Rijli - rijli@igbmc.u-strasbg.fr; Jean Champagnat* - Jean.Champagnat@iaf.cnrs-gif.fr

* Corresponding author
\end{abstract}

Published: 26 September 2007

Neural Development 2007, 2:19 doi:10.1186/1749-8104-2-19
Received: 10 April 2007

Accepted: 26 September 2007

This article is available from: http://www.neuraldevelopment.com/content/2/1/19

(c) 2007 Chatonnet et al.; licensee BioMed Central Ltd.

This is an open access article distributed under the terms of the Creative Commons Attribution License http://creativecommons.org/licenses/by/2.0, which permits unrestricted use, distribution, and reproduction in any medium, provided the original work is properly cited.

\begin{abstract}
Background: Little is known about the involvement of molecular determinants of segmental patterning of rhombomeres $(r)$ in the development of rhythmic neural networks in the mouse hindbrain. Here, we compare the phenotypes of mice carrying targeted inactivations of Hoxa2, the only Hox gene expressed up to $r 2$, and of Krox 20 , expressed in $r 3$ and $r 5$. We investigated the impact of such mutations on the neural circuits controlling jaw opening and breathing in newborn mice, compatible with Hoxa2-dependent trigeminal defects and direct regulation of Hoxa2 by Krox20 in r3.

Results: We found that Hoxa2 mutants displayed an impaired oro-buccal reflex, similarly to Krox20 mutants. In contrast, while Krox 20 is required for the development of the rhythm-promoting parafacial respiratory group (PFRG) modulating respiratory frequency, Hoxa2 inactivation did not affect neonatal breathing frequency. Instead, we found that $\mathrm{Hoxa2} 2^{-/-}$but not $\mathrm{Krox} 2 \mathrm{O}^{-/-}$mutation leads to the elimination of a transient control of the inspiratory amplitude normally occurring during the first hours following birth. Tracing of $\mathrm{r} 2$-specific progenies of $\mathrm{Hoxa} 2$ expressing cells indicated that the control of inspiratory activity resides in rostral pontine areas and required an intact $r 2$-derived territory.

Conclusion: Thus, inspiratory shaping and respiratory frequency are under the control of distinct Hox-dependent segmental cues in the mammalian brain. Moreover, these data point to the importance of rhombomere-specific genetic control in the development of modular neural networks in the mammalian hindbrain.
\end{abstract}




\section{Background}

The role of hindbrain segmentation [1] in the organization and function of neural networks has been investigated using mutant mouse models for key regulatory genes, of which members of the Hox gene family are important. These genes display partially overlapping expression domains with rostral limits matching rhombomere (r) boundaries, providing a specific expression code for each segment along the anterior-posterior (AP) axis (reviewed in $[1,2]$ ). Segment-specific Hox expression is regulated by transcription factors exhibiting rhombomere-restricted expression patterns, such as Krox20 expressed in $\mathrm{r} 3$ and $\mathrm{r} 5$ [3-5], and by cross- and auto-regulatory activity of Hox proteins themselves [6-8]. Defining the biological significance of these rhombomere-specific gene regulatory networks is essential for understanding the development and functional organization of neuronal circuits in the vertebrate hindbrain. Hoxa2 is particularly interesting as it is the most anteriorly expressed Hox gene up to the $\mathrm{r} 1 / \mathrm{r} 2$ border, and because it participates in complex rhombomere-specific regulatory pathways $[6,9]$. Targeted inactivation in the mouse revealed that Hoxa2 is indeed required for normal patterning of the rostralmost rhombomeres, as well as for the development of topographic brainstem circuitry [10-13]. However, the behavioral implication of Hoxa2 control has not yet been addressed.

A very sensitive method to evaluate behavioral significance of disturbed rhombomere development is to identify uncompensated abnormalities of vital postnatal behavior, for example, alimentary and breathing behaviors, in vivo in transgenic animals. The oro-facial control in particular is tightly linked with trigeminal sensory and motor pathways, as well as surrounding rhythmogenic and pre-motor reticular neurons [14-16]. Interestingly, mutations affecting rostral hindbrain segmentation differentially affect the control of jaw opening in neonates, which requires Krox20 [17] but not Hoxa1 expression [18]. A recent study [13] showed that Hoxa2 controls the connectivity pattern of the trigeminal sensory afferents to the rostral pons governing the formation of the whisker-tobarrel somatosensory circuit in the mouse. The implication of the Hoxa2 mutation on oro-buccal behavior remains to be investigated in these mice.

Breathing in rodents is thought to be governed by a rhythm generator named the pre-Bötzinger Complex (preBötC) $[19,20]$, which acts as an oscillator. Previous studies from our group showed that it arises from post-otic rhombomeres [21,22]. The most recent findings support an additional parafacial respiratory group (pFRG) [23], which also shows an oscillating rhythmic activity. A dual origin of respiratory rhythm generation in newborn rodents involving a coupling between the pre-BötC and the pFRG [24] has been hypothesized and the roles of each oscillator in respiratory rhythm generation are still under discussion [25].

We have used the above-mentioned developmental approach to investigate the origin and the architecture of the respiratory rhythm generator. We previously described life-threatening anomalies of respiratory frequency that can be alleviated by naloxone in Krox $20 \%$ and Hoxa $1 \%$ mice. In these mice an anti-apneic system that exerts a rhythm-promoting function during the first postnatal days, likely the pFRG, is eliminated $[17,18,26]$. Krox20dependent signaling and the $\mathrm{r} 3-\mathrm{r} 4$ segment are required in chicken and mice for the development of the pFRG [27].

In addition to the pre-BötC and the pFRG, the rostral pons has a role in control of breathing but its function in the intact animal remains questionable (see [28]). Distinct pontine inspiratory control in vivo has been recently proposed, the development of which can be altered by retinoic acid at embryonic day (E) 7.5 without affecting the respiratory frequency [29]. The present study investigates in vivo whether anti-apneic and inspiratory controls result from different AP specifications (Krox20-dependent, parafacial [26], and rostral [29], Hoxa2-dependent, respectively) caudal to the $\mathrm{r} 2 / \mathrm{r} 3$ boundary. Alternatively, the present study also considers that abnormal inspiratory control in vivo may result from behavioral adaptation to r3-r5 defects in which Krox20 expression is altered but not entirely eliminated. These two hypothesis are investigated comparing Krox20 null mutant mice with null Hoxa2 [10] and hypomorphic Krox20 [30] mutant mice. We found that inactivation of either Hoxa2 or Krox20 impairs the rhythmic control of the jaw opening in agreement with HOXA2-dependent trigeminal defects and direct regulation of Hoxa2 by KROX20 in r3. However, an inspiratory pontine activity residing in the rostral pons and requiring an intact $\mathrm{r} 2$ is selectively abolished in Hoxa2 $\%$, but not in Krox20, mutants. These results indicate that pontine inspiratory and para-facial anti-apneic control systems are embryologically and functionally distinct and are under the control of distinct Hox-dependent segmental cues in the mammalian brain.

\section{Results \\ Impairment of oro-buccal behavior in Hoxa2-I- mice at birth}

To investigate oro-buccal behavior, we counted the number of jaw openings elicited by an oral stimulation in Hoxa $2 \%$ mice and compared the phenotype to that of Krox $20 \%$ - mice. In Krox $20 \%$ - mice, a reduction by about $50 \%$ of the number of jaw openings indicated an alteration of the trigeminal pre-motor and/or motor control, normally originating in the r2-r3 region [17]. In Hoxa $2 \%$ mutant mice, we found that the number of jaw openings during 
$30 \mathrm{~s}$ was decreased by $45 \%(P<0.0001)$, ranging from 13.6 at postnatal day (P)0 to 16.6 at P0.5, significantly less than values of 24 at P0 and 32 at P0.5 measured in the wild-type (Table 1). Elicitation of jaw opening was normal in Hoxa2+/- (Table 1) and Krox20 hypomorphic mutants (22 during $30 \mathrm{~s}(\mathrm{n}=7)$ versus 25 in the wild-type $(n=17))$, indicating that full inactivation of either gene was required to affect behavior. The small number of evoked jaw openings at P0, coupled with the respiratory impairment described below, defined a highly penetrant (72\%; 16 out of 22 homozygous mutants; Figure 1b,c) functional phenotype in Hoxa $\%$ mutant mice.

\section{Compared with the Krox20 null mutation, the Hoxa2--- mutation selectively affects the inspiratory amplitude without affecting respiratory frequency during the first postnatal hours}

At P0.1, the tidal volume per body weight of Hoxa2\%homozygous mutants was twice as large as that of the wild-type or Hoxa2+/- heterozygous mutant mice (Table 1). Samples of plethysmographic recordings (Figure 1a) show that this increase in respiratory amplitude (tidal volume $\left(\mathrm{V}_{\mathrm{T}}\right)$ ) was not compensated for by any decrease in respiratory frequency, which was similar in the three genotypes at P0.1 (Table 1). Consequently, Hoxa2-/- animals exhibited a greater than normal average respired volume (minute ventilation $\left.\left(V_{E}\right)=f_{R} \times V_{T}\right)$ at P0.1 (Table 1). Since there was no consistent difference in the duration of inspiration $(\mathrm{Ti})$, these animals also showed a greater than normal inspiratory flow $\left(\mathrm{V}_{\mathrm{T}} / \mathrm{Ti}\right)$. This was very different from the observations in the Krox20 null mutant mice, which showed a $\mathrm{V}_{\mathrm{T}}$ similar to their wild-type littermates (Figure 2b) during the first postnatal days.

In human infants, the first inspiratory efforts are the deepest breaths of the whole neonatal period [31-33]. The $\mathrm{V}_{\mathrm{T}}$ is later reduced and increases afterwards progressively during several hours (see page 26 of [34]). The same was observed in the wild-type (Figure $2 \mathrm{a}, \mathrm{b}$ and inset) and Krox $20^{-/}$(Figure 2b) mice, in which values of $\mathrm{V}_{\mathrm{T}}$ were reduced to about $5 \mu \mathrm{l} / \mathrm{g}$ at $\mathrm{P} 0.1$ and increased to about 10 $\mu \mathrm{l} / \mathrm{g}$ at P0.5, which is the normal value maintained during the postnatal week (Figure 2a, b). At P0.5, the absolute tidal volume values of all genotypes were very similar, ranging from $8-11 \mu \mathrm{l} / \mathrm{g}$. The tidal volume of Hoxa2-/mutant mice was the same as at birth, indicating that the decrease in $\mathrm{V}_{\mathrm{T}}$ observed in wild-type mice after the first breaths was impaired by the mutation (Figure 2a). Thus, the Hoxa2 invalidation perturbs a developmentally regulated mechanism involved in the control of the tidal volume during the first 12 postnatal hours.

Respiratory frequency $\left(\mathrm{f}_{\mathrm{R}}\right)$ also changed during the first day but increased only by about $50 \%$ (Figure $3 a$ ). The values of respiratory frequency at birth were about the same in Hoxa $2 \%$ mutants as in wild-type animals and both showed an increase in frequency between P0.1 and P0.5 (Table 1, Figure 3a). The changes of $\mathrm{V}_{\mathrm{T}}$ during the first hours were, therefore, mostly responsible for the modifications of the $\mathrm{V}_{\mathrm{E}}$ and both were abolished in Hoxa2-/mutant mice. This contrasted with the respiratory phenotype associated with the Krox20 null mutation resulting in a respiratory frequency $60 \%$ less than in the wild-type (42

Table I: Respiratory parameters and anatomical measures of wild-type, heterozygous and homozygous Hoxa2 mutant mice at birth

\begin{tabular}{|c|c|c|c|}
\hline & Wild-type & Heterozygous & Homozygous \\
\hline \multicolumn{4}{|c|}{ Respiratory and behavioral parameters at PO.I } \\
\hline $\mathrm{N}$ & 38 & 58 & 29 \\
\hline Birth weight (g) & $1.45 \pm 0.006$ & $1.46 \pm 0.022$ & $1.40 \pm 0.024$ \\
\hline \multicolumn{4}{|l|}{ Weight gain at $\mathrm{P} 0.75$} \\
\hline Grams & $0.24 \pm 0.01$ & $0.22 \pm 0.01$ & $-0.09 \pm 0.008^{*}$ \\
\hline Percent & $16.5 \pm 1.0$ & $15.1 \pm 0.9$ & $-6.6 \pm 0.6^{*}$ \\
\hline Jaw openings (in $30 \mathrm{~s}$ ) & $24.0 \pm 0.41$ & $23.9 \pm 1.22$ & $13.6 \pm 1.63 *$ \\
\hline$f_{R}$ (cycles/minute) & $107 \pm 1.3$ & $107 \pm 4.0$ & $110 \pm 5.7$ \\
\hline Tidal volume $(\mu \mathrm{l} / \mathrm{g})$ & $4.6 \pm 0.06$ & $5.3 \pm 0.41$ & $10.6 \pm 0.87^{*}$ \\
\hline $\mathrm{V}_{\mathrm{E}}(\mathrm{ml} / \mathrm{g} /$ minute $)$ & $0.52 \pm 0.01$ & $0.58 \pm 0.06$ & $1.21 \pm 0.14^{*}$ \\
\hline Apneas (\% of recording duration) & $1 \mathrm{I} \pm 0.8$ & $9.6 \pm 3.0$ & $8.1 \pm 3.7$ \\
\hline \multicolumn{4}{|l|}{ Anatomical measures } \\
\hline $\mathrm{N}$ & 8 & 4 & 12 \\
\hline AP length of locus coeruleus $(\mu \mathrm{m})$ & $455 \pm 18$ & $420 \pm 60$ & $717 \pm 23 *$ \\
\hline DV height of locus coeruleus $(\mu \mathrm{m})$ & $625 \pm 60$ & $700 \pm 20$ & $1,017 \pm 73 \dagger$ \\
\hline Distance between $L C$ ventral limit $(\mu \mathrm{m})$ & $1,050 \pm 25$ & Not measured & $607 \pm 79 *$ \\
\hline
\end{tabular}

Values are given as mean \pm standard error of the mean. $f_{R}$, respiratory frequency; $V_{E}$, minute ventilation. Tidal volume at birth was increased twofold in Hoxa2-- mice (see also Figure 2), but this feature disappeared rapidly: $V_{E}$ at $P 0.75$ was not significantly different between the three genotypes. Note that Hoxa2-- mice lost weight between birth and P0.75, while their wild-type and heterozygous littermates gained weight. The birth weight and respiratory frequency are not significantly different. $* P<0.00 \mathrm{I} ; \mathrm{\uparrow} P<0.0 \mathrm{I}$. DV, dorso-ventral; LC, locus coeruleus. 

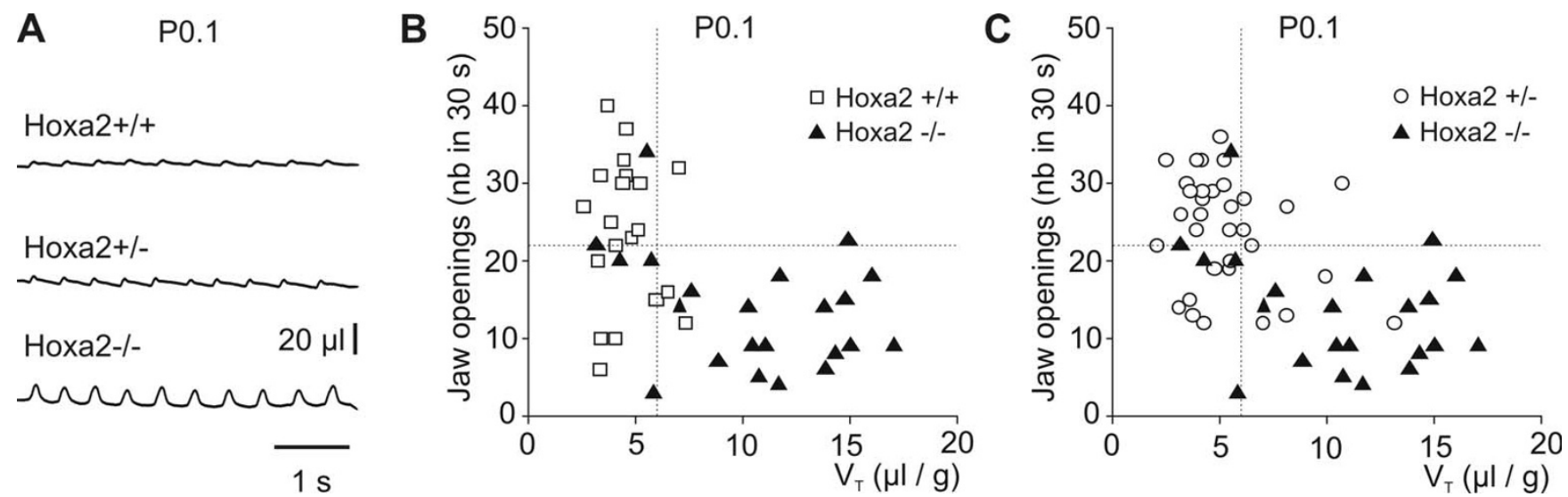

Figure I

Phenotypic traits of Hoxa2-/- mutants at birth: impaired oro-buccal behavior and increased tidal volume. (a) Plethsymographic recordings of wild-type (top), and heterozygous (middle) and homozygous (bottom) Hoxa2 mutant mice at P0. Inspiration is upward. Note that in Hoxa2-/- mice, there is a two-fold increase in tidal volume compared with Hoxa2 $2^{+/-}$and wild-type littermates, whereas the frequency is the same (about I I 0 breaths/minute). (b, $\mathbf{c}$ ) Individual data relating tidal volume $\left(\mathrm{V}_{\mathrm{T}}\right.$, abscissa) and number $(\mathrm{nb})$ of jaw openings (ordinates) at P0.I. Each symbol corresponds to one animal. Black triangles are for Hoxa2-/mutants $(b, c)$, open circles represent Hoxa2 $2^{+/-}$mutants (c) and open squares correspond to wild-type animals (b). Note that Hoxa2-- mutants can be separated from other genotypes at P0.I, due to their two-fold increased tidal volume and their reduced number of jaw openings. Broken lines indicate the values used to calculate penetrance of the phenotype $\left(\mathrm{V}_{\mathrm{T}}\right.$, all data inferior to mean - I standard deviation; jaw openings, all data superior to mean + I standard deviation).

\pm 24 breaths/minute at P0.5, $\mathrm{n}=17$; Figure $3 \mathrm{~b})$. Very long apneas (> $3 \mathrm{~s}$ ) were frequently observed and an increase in inspiratory flow did not compensate for the decreased frequency, thus minute ventilation at P0.5 $(0.48 \pm 0.38 \mathrm{ml} /$ $\mathrm{g} /$ minute, $\mathrm{n}=17$ ) was less than half the wild-type values $(1.10 \pm 0.79 \mathrm{ml} / \mathrm{g} /$ minute, $\mathrm{n}=25)$.

Thus, the respiratory phenotype of the Krox20 null mutation was dramatically distinct from that observed in Hoxa2 null mutants. Hoxa2 null mutation specifically affected the inspiratory control at birth, without modifying the respiratory frequency, whereas Krox20 null mutation had the exact opposite effect, deeply affecting the respiratory frequency without changing the respiratory amplitude.

\section{Partial impairment of Krox20 function does not mimic the Hoxa2--- respiratory phenotype and preserves breathing rhythm at birth}

Krox20 is required for the development of r3, where Hoxa2 is expressed under Krox20 control [4]; nevertheless, the respiratory phenotype of the Krox20 null mutation was quite distinct from that observed in Hoxa2 null mutants (see above), suggesting that it was not induced by the loss of Hoxa2 expression in r3. However, as the Krox20 mutation results in the complete elimination of $\mathrm{r} 3$, it cannot be compared to the changes induced in the Hoxa2 null mutants, in which $\mathrm{r} 3$ is still present but displays patterning defects $[10,11]$. The abnormal inspiratory control in Hoxa2 mutants might, therefore, originate from an adap- tive respiratory behavior following compensation for the loss of Hoxa2 in r3, while Krox20 is still functional.

To investigate this possibility we analyzed Krox $20^{\text {Cre/flox }}$ hypomorphic mutants resulting in a reduced, though not absent, r3 territory. This hypomorphic mutant was obtained by combining two previously developed Krox20 alleles, a Cre knock-in and a floxed allele (see Materials and methods for detailed description). Compound heterozygous Krox $20^{\text {Crelflox }}$ mutants express Krox20 only transiently and, in the hindbrain, this results in a severe reduction of $\mathrm{r} 3$ (Figure 4 ). Analysis of the Krox $20^{\text {Cre/flox }}$ mutants revealed that the tidal volume was normal (115\% of controls) as well as the respiratory frequency (P0.5: $101 \pm 6$ breaths/minute $(\mathrm{n}=7)$ compared to $114 \pm$ 10 breaths/minute $(\mathrm{n}=17)$ in wild-type littermates; Figure 4) and the duration of apneas during the first postnatal day. Therefore, partial impairment of Krox 20 function, resulting in a severe reduction of $\mathrm{r} 3$, is compatible with a normal control of the respiratory rhythm at birth and does not reproduce the Hoxa2 null phenotype characterized by the absence of a transient decrease in tidal volume around birth.

Because development of rhythmic circuits in r3r4 has been ascribed to $\mathrm{r} 3$-related control of neurogenesis in $\mathrm{r} 4$ [27], we analyzed the early pattern or neuronal differentiation in Krox20Cre/flox mutants (Figure 4c, d). We found that $\mathrm{r} 3$, although dramatically reduced in size, preserves its ability to delay neurogenesis and axonal invasion [35]. 

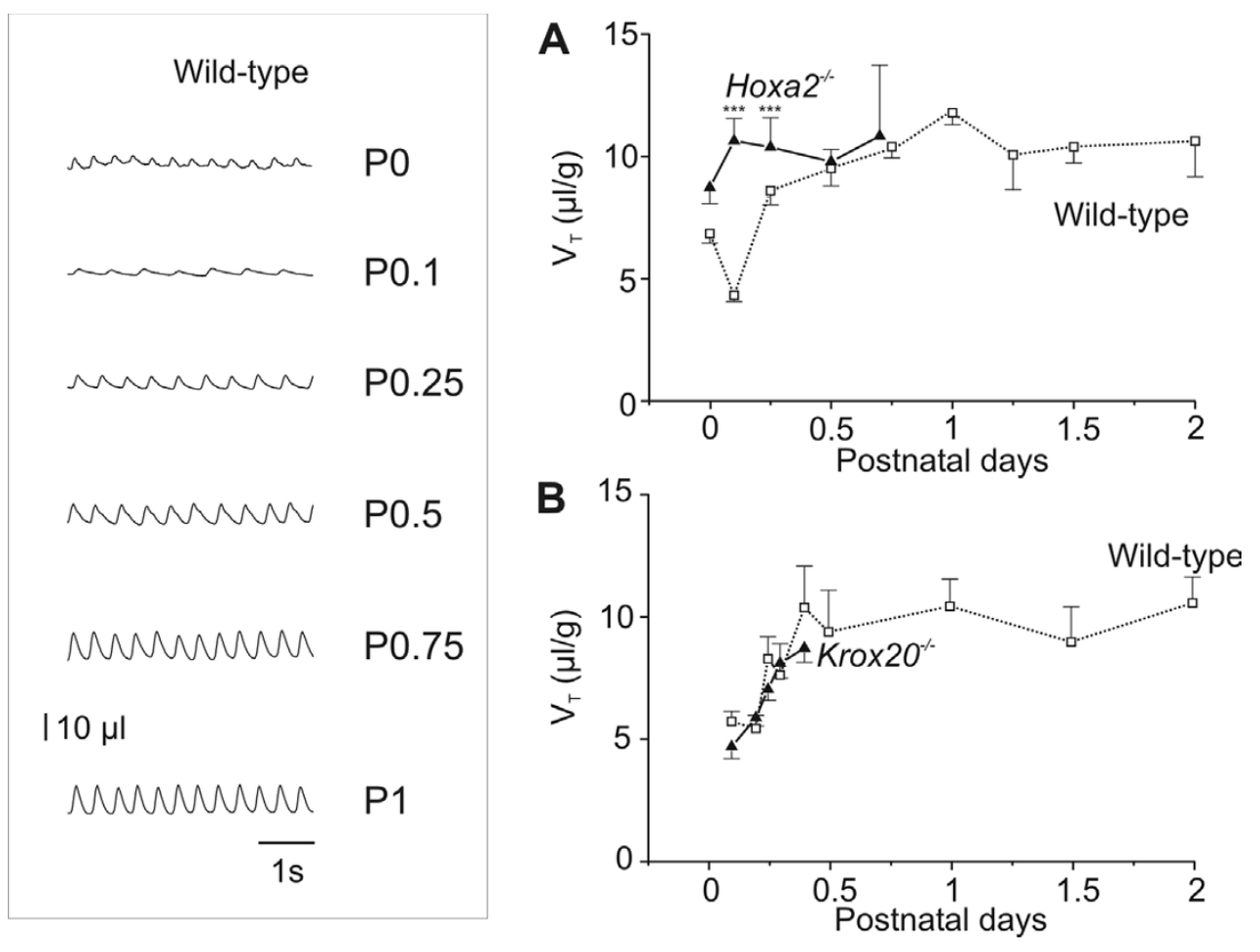

\section{Figure 2}

Tidal volume of Hoxa2-/- and Krox20-/- mutants during the first postnatal days. Inset on the left: plethysmographic recordings of wild-type mice at different times after birth (P0) during the first postnatal day. Inspiration is upward and expiration is downward. Note the evolution of tidal volume (respiratory amplitude) and respiratory frequency during the first day. Calibration bars: abscissa, I s; ordinates, $10 \mu \mathrm{l}$. Graphs present the evolution of mean \pm standard error of the mean. Tidal volume $\left(\mathrm{V}_{\mathrm{T}}\right)$ in wild-type mice (open squares, dotted line) and (a) Hoxa2-/- and (b) Krox20-/- mutants (black triangles, continuous line) during the first two days after birth. All mutants were dead shortly after P0.75, therefore explaining the lack of further data. Note that in wild-type and Krox $20^{-/-}$animals, tidal volume rapidly increased during the first 12 hours of life whereas in Hoxa2-/- mice, tidal volume was already two-fold greater at P0.I. ***P $<0.001$.

We conclude that function of the anti-apneic control does not depend on the ability to maintain quantitatively the size of embryonic territories, but rather as previously suggested [27], on odd-numbered rhombomere properties required to qualitatively control neuronal circuit formation.

Taken together, these results establish that Hoxa2 does not mediate the Krox20 null respiratory phenotype in r3 since Hoxa2 null mutation does not reproduce Krox20 null mutation phenotypic traits. In addition, they suggest that the Hoxa2 mutant respiratory phenotype may be contributed by abnormalities in pontine areas more rostral than the Krox20 phenotype, since Hoxa2 has greater effects in its rostral domain of expression [10,36].

\section{Apneas are not responsible for the lethality of the Hoxa2- I- mutation}

At P0, the respiratory pattern was very irregular in Hoxa2-/ - mutant mice and the time spent in apneas (that is, respi- ratory pauses lasting more than $2 \mathrm{~s}$ ) was about $10 \%$ of the total time of observation, similar to heterozygous and wild-type animals (Table 1). At P0.5, the time spent in apneas in wild-type animals normally decreased to $3.2 \pm$ $2.0 \%$ of the recording time. In contrast, no decrease was observed in Hoxa2 $\%$ mutants (time spent in apneas at P0.5, $17.5 \pm 5.5 \%$ ) and at P0.5 these animals spent significantly more time in apneas than controls. However, apneas did not greatly influence the average volume inhaled by Hoxa2-/- mutants. At P0.5, shortly before the death of the animals, the minute ventilation in homozygous mutants $(1.36 \pm 0.42 \mathrm{ml} / \mathrm{g} / \mathrm{minute})$ was not significantly different from that at birth $(1.21 \pm 0.14 \mathrm{ml} /$ $\mathrm{g} / \mathrm{minute})$ or from that in the wild-type $(1.71 \pm 0.11 \mathrm{ml} /$ $\mathrm{g} /$ minute $)$ or heterozygous $(1.43 \pm 0.09 \mathrm{ml} / \mathrm{g} /$ minute $)$ littermates.

Interestingly, administration of naloxone at P0.5 failed to improve survival of Hoxa2\% mutants (Figure 5), unlike Krox $20 \%$ and Hoxa $1 \%$ mutants $[17,18]$. In both wild-type 
A

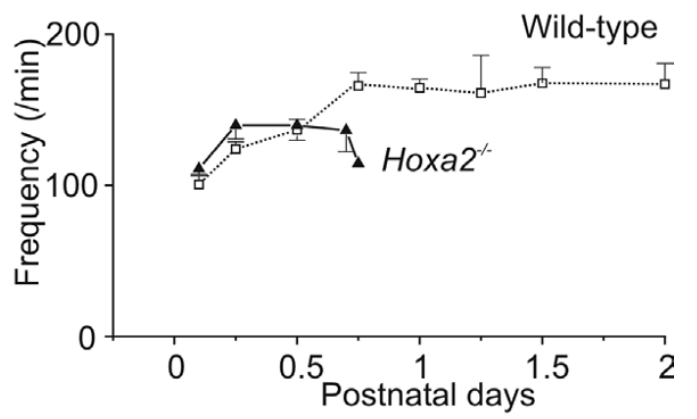

B

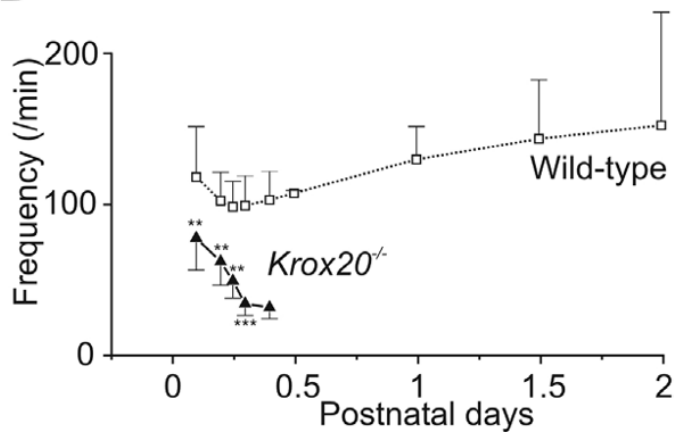

Figure 3

Respiratory frequency of $\mathrm{Hoxa2}^{-/-}$and $\mathrm{Krox} 2 \mathrm{O}^{-/-}$mutants during the first postnatal days. Graphs present the evolution of mean \pm standard error of the mean respiratory frequency in wild-type mice (open squares, dotted line) and (a) Hoxa2-/and (b) Krox20-/- mutants (black triangles, continuous line) during the first two days after birth. All mutants were dead shortly after $\mathrm{P} 0.75$, therefore explaining the lack of further data. Deficiency of the respiratory frequency is lethal in Krox 20-/- [17]; frequency is normal in Hoxa2 $2^{-/}$mutants. ${ }^{*} * P<$ 0.01 , $* * * p<0.001$.

and heterozygous Hoxa2 mutant animals, naloxone treatment had no significant effects on the breathing pattern. In the homozygous Hoxa $\%$ mutant mice ( $\mathrm{n}=7$ ), naloxone injection at P0.5 slightly increased respiratory frequency from 135 breaths/minute to 177 breaths/ minute (Figure 5b) and eliminated apneas (Figure 5a). Despite these stimulating effects upon ventilation, none of the treated Hoxa2 $\%$ mutants lived more than 18 hours (Figure 5c), the maximum lifetime observed in untreated Hoxa2 $\%$ animals. Altogether, these results demonstrate that apneas do not greatly influence the respiratory minute ventilation and are not responsible for lethality of the Hoxa2 mutation.
Krox20

Krox $20^{\text {cre/flox }}$
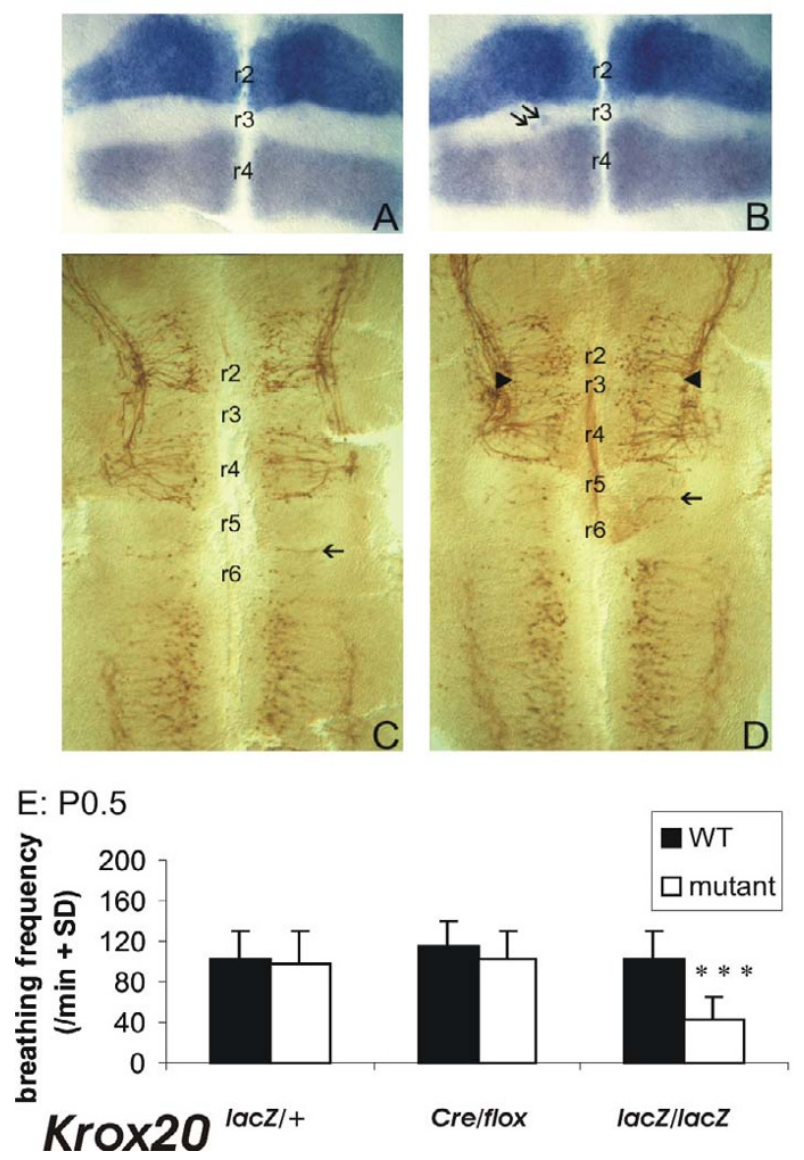

Figure 4

$\mathrm{r} 3$ and $\mathrm{r} 5$ are reduced in size in Krox20 Cre/flox embryos. (a, b) The size of $r 3$ was estimated at E9.5 on flat-mounted hindbrains by labeling adjacent rhombomeres. $r 4$ was delimited by in situ hybridization with a Hoxb / probe and $\mathrm{r} 2$ by detection of the alkaline phosphatase activity from an $r 2$-specific transgene [47, 48]. The negative territory located in between corresponds to $\mathrm{r} 3$ and is reduced in $\mathrm{Krox} 2 \mathrm{O}^{\mathrm{Cre} / f l o x}$ (b) compared to control Krox20Cre/+ (a) embryos. A few Hoxbl-positive cells are also observed within $r 3$ in embryos (arrows). (c, d) Flat mounts of Krox20 Cre/+ (c) and Krox20 Crelflox (d) hindbrains immunolabeled with an antibody directed against the I $55 \mathrm{kDa}$ component of neurofilaments $(2 \mathrm{H} 3) . \mathrm{r} 3$ and $\mathrm{r} 5$ can be distinguished from even-numbered rhombomeres by their less advanced differentiation of reticular neurons, revealed by lower neurofilament immunoreactivity. The $r 5 / r 6$ boundary is clearly visible since it is followed by axons (arrow in (c, d)). Both $r 3$ and $r 5$ are reduced in Krox20Cre/flox embryos, the effect being more dramatic in $r 3$ (arrowheads). (e) Breathing frequency at birth in heterozygous Krox20 laczl+ (left) and in Krox20Cre/flox (middle) mice is the same as in wild-type mice (WT, white columns); it is lower than normal in homozygous Krox20lacZllacZ mice (right). *** : $\mathrm{p}<0.001$ 


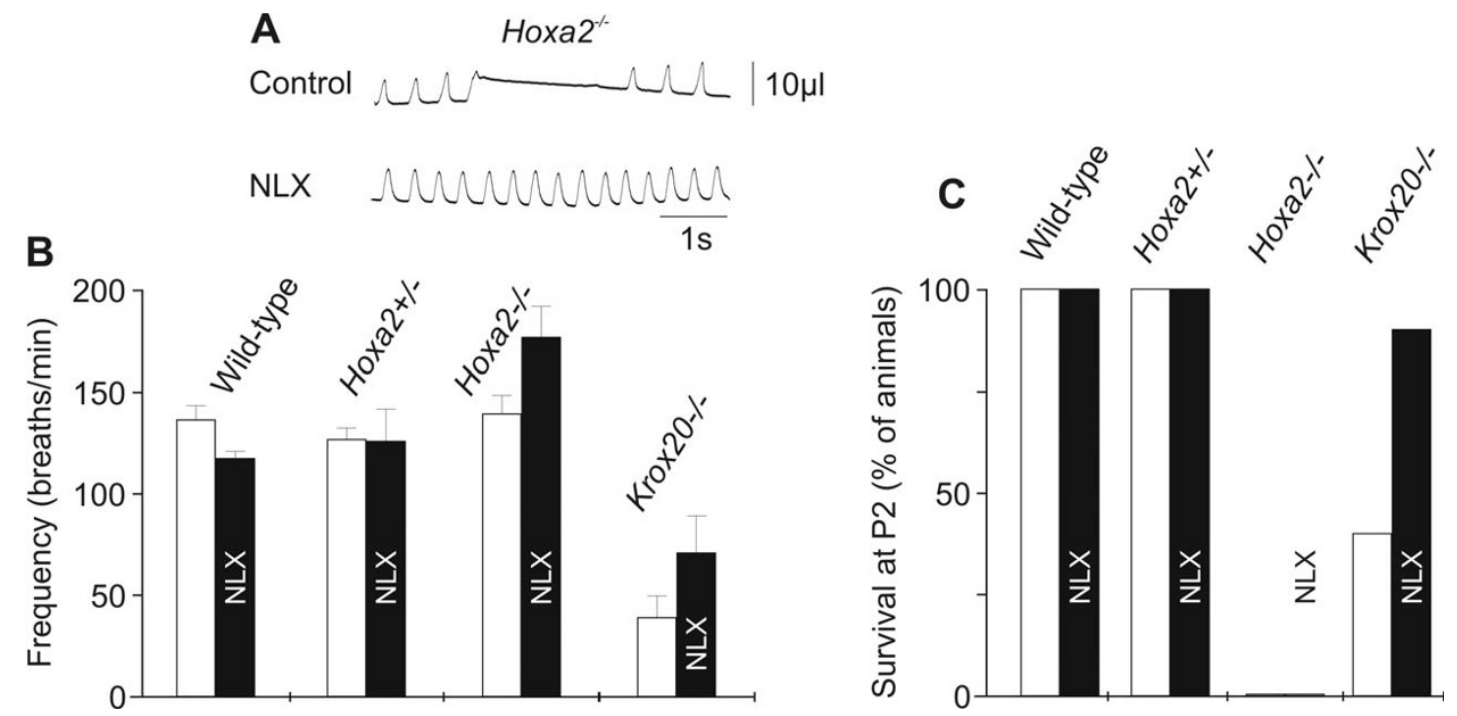

\section{Figure 5}

Naloxone treatment was effective on ventilation in Hoxa2-/- mice but did not increase survival. (a) Plethysmographic recordings before (control) and after naloxone (NLX) treatment in Hoxa2-/- animals. Note the frequency increase and the reduction of apneas. (b, c) Effects of the subcutanueous injection of $\mathrm{NLX}(\mathrm{I} \mathrm{mg} / \mathrm{kg})$ at P0.5 upon mean \pm standard error of the mean respiratory frequency calculated without apneic episodes in wild-type, Hoxa2+/-, Hoxa2-/- and Krox20-/- animals (b) or survival in the same genotypes (c). In (b, c) white bars indicate control values and black bars labeled NLX indicate values in the same animals one hour (b) (respiratory frequency) or 1.5 days (c) (survival) after NLX injection. Although NLX eliminates apneas (a) and increases respiratory frequency (by $3 \mathrm{I}+\mathrm{I}$ I\% in Hoxa2-/- and $5 \mathrm{I} \pm 37 \%$ in Krox $20^{-/-}$) (b), it does not allow survival of Hoxa2-/mutants (c).

\section{Anatomical defects in rostral pontine areas in Hoxa2--- mutants}

We analyzed the distribution of Enhanced Green Fluorescent Protein positive (EGFP+) cells in knock-in mice in which EGFP expression was selectively induced in r2derived Hoxa2 expressing cells upon Cre-mediated recombination, by mating the Hoxa2 EGFP(lox-neo-lox) knock-in allele with a r2-specific Cre transgenic line [12] (Figure 6a, b, d, $\mathrm{e}, \mathrm{g}$; see also Materials and methods). This mating scheme resulted in full Hoxa2 targeted inactivation, and, concomitantly, allowed selective tracing of the Hoxa2-expressing $\mathrm{EGFP}^{+}$cells only in the r2-derived progeny.

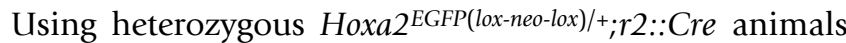
at E18.5, we showed that the estimated lateral parabrachial medial and Kölliker-Fuse nuclei (Figure 6b, e), as well as the more medial noradrenergic locus coeruleus, identified by PHOX2A or tyrosine hydroxylase (Figure $6 \mathrm{~g}$ ), were located outside, though adjacent to, the trigeminal r2-derived domain. Therefore, the putative inspiratory related domain is derived from $r 1$, about two rhombomeres distant from the r3-r4 region, the most anterior site known to induce formation of a respiratory frequency controller $[17,26]$.

Analysis of EGFP expression in E18.5 Hoxa2 EGFP(lox-neo-lox)/; $r 2::$ Cre homozygous mutant mice (Figure 6c, f, h) indi- cated that the r2-derived peri-trigeminal nuclei were reduced while a ventral hyperplasia of the estimated Kölliker-Fuse (KF in Figure $6 \mathrm{a}-\mathrm{c}$ ) and parabrachial medial (PB in Figure 6d-f) nuclei was observed (arrowheads in Figures $5 \mathrm{f}$ and $6 \mathrm{c}$ ). Other r1-derived structures, such as the locus coeruleus (LC in Figure $6 \mathrm{c}$ and Table 1) and the pediculo-pontine tegmental nuclei also expanded ventrally.

The anatomical structures modified in Krox $20^{-/}$, Hoxa1-/ and kreisler mutants $[17,18,29,37]$ have also been investigated in Hoxa2\%- neonates. Specifically, we found a normal morphology of the anterior fourth ventricle, a normal AP length of the dorsal Pons, and a normal position of the ambiguus and facial branchial motor nuclei (data not shown). The parvocellular reticular nucleus, a dorsal pontine structure originating in $\mathrm{r} 3$ and extending between the trigeminal motor nucleus and the facial nerve $[17,18,29]$ was also normal in Hoxa2\%- mutants.

In conclusion, the brainstem defects likely responsible for the observed abnormalities of inspiratory control are restricted to the rostral pons of Hoxa2\%-mutants and include the r1-r2 derived territory. 


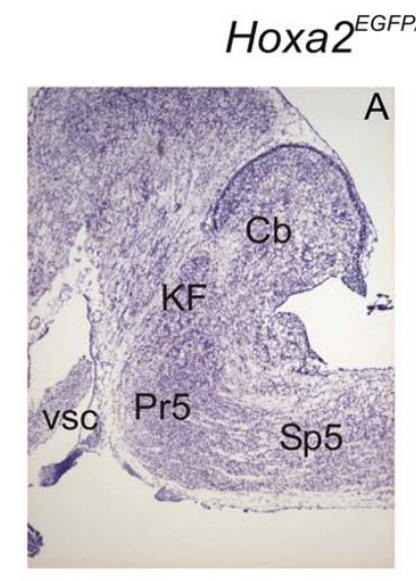

${ }^{p /+} ;$ r2::Cre

Hoxa2 ${ }^{\text {EGFP/ }} ; r 2::$ Cre
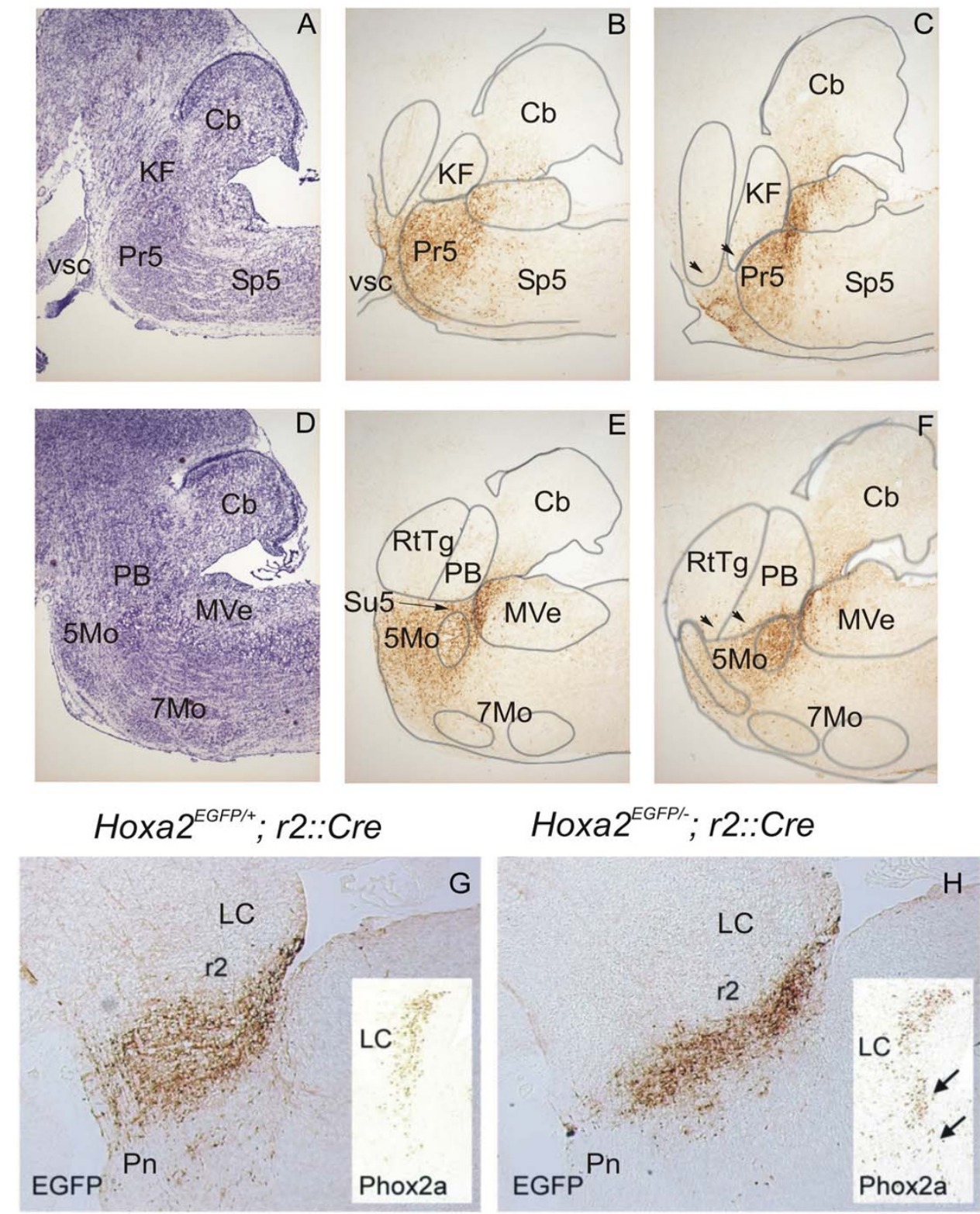

\section{Figure 6}

Hyperplasia of the $\mathrm{rl}$-derived dorsal pontine tegmentum in Hoxa2-/- mutants. Para-sagittal sections of the brainstem of (a, b, $\mathbf{d}$, e, g) Hoxa2EGFP(lox-neo-lox)/+;r2::Cre (labeled Hoxa2EGFP/+;r2::Cre) or (c, f, h) Hoxa2EGFP(lox-neo-lox)/-;r2::Cre (labeled Hoxa2EGFPl-;r2::Cre) El 6 mice at different latero-medial levels, from more lateral (KF level) (a-c), to more medial (LC level) (g, h) through an intermediate level (trigemino-facial level) $(\mathrm{d}, \mathrm{e}) .(\mathbf{a}, \mathbf{d})$ Violet cresyl stainings from which the delimitations of the different brainstem nuclei appearing as lines in other panels were drawn. (b, $\mathbf{c}, \mathbf{e}, \mathbf{f})$ Immunodetection of EGFP, showing r2-derived cells. Note the reduction of the $\mathrm{r2}$-derived domain and the ventral expansion of $\mathrm{rl}$-derived nuclei such as the estimated $\mathrm{KF}$ (arrowheads in (c)), PB and RtTg (arrowheads in (f)) in Hoxa2EGFP(lox-neo-lox)/-;r2::Cre mice. (g, h) Immunodetection of EGFP at the LC level showing reduction of the $r$-derived territory in Hoxa2EGFP(lox-neo-lox)/-;r2::Cre; insets show immunodetection of PHOX2A, a marker for the LC noradrenergic neurons - note the ventral expansion in Hoxa2EGFP(lox-neo-lox)/-;r2::Cre mice (arrows in (h)). 5Mo, trigeminal motor nucleus; 7Mo, facial motor nucleus; Cb, cerebellum; KF, estimated position of the Kölliker-Fuse nucleus; LC, locus coeruleus; MVe, medial vestibular nucleus; PB, estimated position of the parabrachial nucleus; Pn, pontine nuclei; Pr5, principal sensory trigeminal nucleus; RtTg, reticulo-tegmental nucleus of the pons; Sp5, spinal trigeminal tract; Su5, supratrigeminal nucleus; vsc, ventral spinocerebellar tract. 


\section{Discussion \\ The Hoxa2 mutation affects the development of the rostral pons}

Consistent with the original observations of the Hoxa2 $\%$ defects being restricted to the anteriormost domain of Hoxa2 expression [10,36], the function of respiratory rhythm controllers located in the caudal pons and medulla was normal in Hoxa $2 \%$ animals. The phenotypic defects of the Hoxa $\%$ mice that were not observed in Krox20 mutants are likely to be related to the reorganization of neural structures derived from the alar plate at the r1-r2 level of the brainstem [10]. The distribution of cells expressing EGFP in the pons of Hoxa $2^{\text {EGFP(lox-neo-lox)/- }}$ ); r2::Cre homozygous mutants pons suggests that the territories derived from $\mathrm{r} 2$ are reduced along the AP axis or have lost r2-specific characteristics. Lack of an r1/r2 boundary [10-12] explains that territories derived from $\mathrm{r} 1$ and adjacent to $\mathrm{r} 2$ are also modified, with, for example, an ectopic projection of the ascending branch of the sensory trigeminal nerve to the cerebellum [13]. The abnormal location of locus coeruleus neurons is also consistent with an altered positioning of neurons within the r1-derived territory [11]. Thus, anatomical observations indicate that a large part of the rostral pontine territory deriving from r1-r2 is reorganized in Hoxa2\%-mutants.

The r1-derived territory adjacent to $\mathrm{r} 2$ includes the estimated location of medial parabrachial and Kölliker-Fuse nuclei where a pontine respiratory group regulates adult mammalian inspirations [38-41] (for review see [28,42]). Therefore, Hoxa 2 might be required for normal development of the pontine respiratory group. Our data further suggest that the pons contributes in shaping inspirations during the first postnatal hours in intact mice in vivo.

In addition, catecholaminergic [43] and cholinergic [44] control of breathing are probably affected. Interestingly, a large $V_{T}$ with normal respiratory frequency in vivo has been observed after the inactivation of the gene encoding acetylcholinesterase, a procedure found to greatly reduce the muscarinic and nicotinic control of the respiratory generator in vitro [44]. It is possible, therefore, that abnormalities of the pediculo-pontine tegmental nucleus (PPTg), the major source of ponto-bulbar cholinergic neurons, contribute to the control of inspirations in Hoxa2 mutants.

Selective inspiratory control by the rostral pons has been postulated to explain postnatal respiratory deficits following the exposure to sub-teratogenic doses of retinoic acid at the onset of hindbrain segmentation (E7.5) [29]. We presently show that development of inspiratory control requires rhombomere-related expression of the most rostral Hox gene in the neural tube. These results further suggest that the genetic network controlling hindbrain segmentation is involved in the formation of neuronal circuits controlling breathing, thereby giving the modular organization of the ponto-bulbar respiratory network [26].

\section{Control of the oro-buccal reflex requires both Hoxa2 and Krox20}

As shown recently, Hoxa2 is required in $\mathrm{r} 2-\mathrm{r} 3$ for trigeminal nerve pathfinding at early stages and axonal arborization of afferents at later stages [13]. Here we show that the anomaly of facial circuits in Hoxa2 $\%$ mutant embryos is associated with an impairment of the reflex-induced rhythmic oro-buccal behavior at birth. Because the Hoxa21- oro-buccal behavior resembles that induced by the elimination of $\mathrm{r} 3$ in Krox $20 \%$ [17], trigeminal behavioral deficits may involve both $\mathrm{r} 2$ - and r3-derived processes, including the Hoxa2-dependent arborization of sensory axons in the rostral principal trigeminal nucleus [13]. In addition, Hoxa2 $\%$ and Krox $20 \%$ deficits may involve rhythmic pre-motor reticular neurons in the vicinity of the trigeminal motor nucleus controlling rhythmic opening of the jaw during alimentary behaviors $[14-16,18]$ http:// www.jneurosci.org/cgi/

external_ref?access_num $=000077737200006 \&$ link_type $=$ ISI. This deficit in suction might participate in the early death of Hoxa2 null mutant mice, impeding the correct feeding behavior together with extensive transformation of the first branchial arch-derived facial skeleton $[2,36]$.

\section{Robustness of Krox20-induced formation of anti-apneic circuits in the mouse}

The most rostral rhombomere that has been shown to be required for the development of normal respiratory rate and to prevent apneas is r3. Elimination of Krox20 expression in $\mathrm{r} 3$ reduces quiet breathing frequency by $50 \%$ and multiplies by 10 the time spent in apnea, eventually leading to opioid-sensitive lethality $[17,26]$. Because, in contrast, hypomorphic Krox20 neonates breathe at a normal rate without apneas, Krox20 expression must be entirely eliminated to alter respiration. Our results, therefore, suggest that the transient expression of Krox20 and the subsequent reduction of $\mathrm{r} 3$ size observed in hypomorphic Krox20 mutants do not prevent the development of the para-facial anti-apneic system. This result extends to mice previous observations in chick embryos using loss- and gain-of function strategies [27]. Krox20 expression in r3 was found necessary for the non-cell autonomous induction of a neuronal rhythm controller from r4 [27]. In contrast, it was found to be unlikely that this induction requires the generation of a specific population of $\mathrm{r} 3$ neurons because KROX20 inhibits (rather than stimulates) neurogenesis and neuronal differentiation [35]. Furthermore, ectopic Krox20-expression in a limited territory (for example, obtained by unilateral electroporation in a rhombomere) was sufficient to induce a fully functional 
rhythm generator, although the population of neurons specified by Krox 20 was certainly smaller than normal r3 in these preparations [27]. We presently show that, in mice as in chicks, induction of the anti-apneic parafacial function by Krox 20 is a robust process that persists despite quantitative alterations of pontine cell populations. Our working hypothesis is, therefore, that Krox20 may act by initiating a cell non-autonomous control of specific neuronal fates rather than by generating a respiratory-related neuronal population in a cell autonomous manner. In addition, rhythm generators may compensate for minor abnormalities during fetal development to restore normal function at birth $[29,44]$. To further explore the parafacial development in mouse embryos, experiments are in progress in our laboratories to identify cell lineages that could be targets of the induction initiated by Krox 20 expression.

\section{Hoxa2 is not a crucial target of Krox20 for the formation of the para-facial neuronal group controlling respiratory frequency}

High levels of Hoxa2 are expressed in r3 and are required at late stages (E13) in trigeminal principal sensory neurons to induce arborization of whisker-related maxillary primary afferents [13]. In contrast, we show that Hoxa2 is not necessary in $\mathrm{r} 3$ for the development of the Krox20dependent anti-apneic respiratory frequency controller; because in Hoxa $\%$ neonates respiratory frequency was normal, apneas were not life-threatening and treatment with naloxone had no effect on survival. In r3, Hoxa2 function downstream of Krox20 may be partially redundant with that of its paralogue Hoxb2 [11], also a direct target of Krox20 [3]. Functional redundancy of Hox2 paralogs can be expected at early developmental stages (endsegmental stages, about E9.5), during which Krox20 expression initiates formation of rhythm generators. Indeed, synergistic genetic interaction of Hoxa2 and Hoxb2 has been shown for the early patterning of r3 [11]. Redundancy might be less at later stages (about E13), when Hoxa2 exerts cell type-specific functions [13]. Previous observations [36] have shown that the anti-apneic activity abolished in Krox20-/ and Hoxa1\%-mutants is preserved in kreisler mutants lacking r5. Altogether, the available data support the location of the anti-apneic activity to be within the para-facial r3r4-derived territories and support Krox20, but not Hoxa2, as a major player in this process.

\section{Conclusion}

We present evidence that distinct circuits regulate respiratory frequency and inspiration depth in vivo and involve different patterning mechanisms and progenitor populations during development. Hoxa2 inactivation, affecting the r1-r2 region and respiratory amplitude, did not severely perturb respiratory rhythm that requires normal Krox20 and Hoxa1 expression in the r3-r5 region [26]. In contrast, inactivation of either Hoxa2 or Krox20 impairs the rhythmic control of jaw opening, consistent with Hoxa2 being required for normal development of the trigeminal function [13] and Krox20 being a direct regulator of Hoxa2 in r3 [4,5].

\section{Materials and methods}

All experiments were carried out following the ethical guidelines of the European Union Council (86/609/EU), the French Agriculture Ministry regulations for the care and use of laboratory animals in acute and chronic experiments. These experiments were also approved by the respective Institution Committees for animal care and handling.

\section{Mouse lines and genotype analysis}

A total of 38 wild-type, 58 Hoxa2+/- and 29 Hoxa2\%- littermates resulting from crosses between heterozygous animals [10-12] were used in the present study. These numbers are in accordance with Mendelian repartition of genotypes ( $\chi^{2}$ test, $\left.P=0.469\right)$. The Hoxa2EGFP(lox-neo-lox) mouse knock-in allele allows selective activation of EGFP expression from the Hoxa2 locus only upon Cre recombinase mediated recombination, as described in [12]. The r2::Cre transgenic line allows selective expression of Cre in r2 and its derivatives, as described in [45]. The original Hoxa2 null mutation is described in [36]. The phenotypes of Hoxa2 $\%$ and Hoxa2 EGFP(lox-neo-lox)/EGFP(lox-neo-lox) homozygous mutants are indistinguishable. The analysis of Hoxa2 EGFP(lox-neo-lox)/+ and Hoxa2EGFP(lox-neo-lox)/- specimens allowed, therefore, the comparison of heterozygous and homozygous Hoxa2 mutants carrying only one dose of EGFP in both genotypes. DNA was extracted from the tail of the neonate mouse and the genotype was subsequently determined by a PCR assay using specific sets of oligonucleotide primers, as described in [12]. All homozygous Hoxa2\%- animals did not feed, lost $6.6 \%$ of their birth weight in their first 18 hours of life and died within 12-20 hours after birth, whereas their heterozygous or wild-type littermates fed, gained about $15 \%$ of their birth weight during the same period, survived (Table 1 ; see also $[36,45])$ and were, therefore, studied during the first week after birth.

We also analyzed 7 hypomorphic Krox20 mutants at P0.5 and P3-4 and we reinvestigated the breathing behavior of 17 Krox $20 \%$ animals [17] during the first hours following birth. The hypomorphic Krox20 mutant was obtained by combining two previously developed Krox20 alleles: the Krox $20^{\mathrm{Cre}}$ allele consists of an insertion of the gene for the Cre recombinase into the Krox20 locus, resulting in Krox20 inactivation and expression of the Cre gene with a pattern that faithfully recapitulates the normal Krox20 pattern [46]; in the Krox20flox allele, the second Krox20 exon is flanked by loxP sites - this allele behaves like the wild- 
type until excision of the floxed exon by the Cre recombinase results in inactivation of Krox $20[30,46]$. The compound heterozygous animals, Krox $20^{\text {Cre/flox, express }}$ Krox20 only transiently, due to subsequent elimination of the second exon. In the hindbrain, this combination behaves as a hypomorphic mutation, resulting in a severe reduction in, but not elimination of, r3, and a slight reduction of r5 (Figure 4 ).

\section{Plethysmographic recordings}

Respiratory activity was measured using a modified barometric method, previously employed in neonates, called whole-body plethysmography [37]. The plethysmograph chamber $(20 \mathrm{ml})$ equipped with a temperature sensor was connected to a reference chamber of the same volume. The pressure difference between the two chambers was measured with a differential pressure transducer connected to a sine wave carrier demodulator. The spirogram was stored on a computer using a Labmaster interface at a sampling frequency of $1 \mathrm{kHz}$. Calibrations were performed at the end of each recording session by injecting 2.5-5 $\mu \mathrm{l}$ of air in the chamber with a Hamilton syringe.

Measurements started 0.5-2 hours after birth and were repeated every 4-6 hours. Neonates were removed individually from the litter and placed in the plethysmograph chamber, which was kept hermetically closed and maintained at $31^{\circ} \mathrm{C}$ during the recording session (165 s). In each sample, periods of quiet breathing were identified by the absence of limb or body movements. Periods of limb, body and head movements were measured to determine neonatal activity during recordings. During quiet breathing, a computer-assisted method was used to measure the duration of inspiration and expiration from which respiratory frequency $\left(f_{R}\right)$ is derived and the tidal volume $\left(V_{T^{\prime}}\right.$ $\mu \mathrm{l} / \mathrm{g})$ from which minute ventilation $\left(\mathrm{V}_{\mathrm{E}}=\mathrm{f} \times \mathrm{V}_{\mathrm{T}} / 1,000\right.$, $\mathrm{ml} / \mathrm{g} /$ minute) is derived. Total duration of apneas per recording session (given in percentages) provided an estimation of the apneic breathing. Apneas were included in the calculation of the minute ventilation, giving a mean value of this physiological parameter. In the case of naloxone treatment, separate calculations of respiratory frequency with and without inclusion of apneas were performed. Naloxone ( $1 \mathrm{mg} / \mathrm{kg}$ in saline) was administered subcutaneously using a Hamilton syringe, and the next recording carried out one hour after injection.

Before plethysmographic recordings, the number of jaw openings within $30 \mathrm{~s}$ was counted by introducing a catheter into the mouth of the newborns, therefore testing orobuccal reflexes [17]. In order to obtain comparable data, counting was done by the same person for the whole study. Both plethysmographic recordings and jaw opening counting were done blindly, without knowing the genotype. Values are given as mean \pm standard error of the mean. Comparisons between two sets of data were performed by paired or unpaired Student's T-tests.

\section{Anatomical observation and immunochemistry}

E18.5 dpc (days post coitum) Hoxa2 EGFP(lox-neo-lox)/+;r2-Cre and Hoxa2 EGFP(lox-neo-lox)/EGFP(lox-neo-lox);r2-Cre foetuses were obtained by caesarean section. Brains were dissected out, fixed in 4\% paraformaldehyde, $1 \times$ phosphate buffer saline (PBS) at $4{ }^{\circ} \mathrm{C}$ overnight, cryoprotected, and sagittally sectioned. Adjacent sections were processed for immunohistochemistry using anti-EGFP (1:2000; Molecular Probes (Carlsbad, California, USA)) or anti-Phox2a (1:1,000; a gift from Jean-François Brunet, ENS, Paris, France) polyclonal antibodies. Sections were then incubated for 2 hours with biotinylated secondary antibodies (1:200, pH 7.4; Vector (Burlingame, California, USA)). Signal amplification was obtained by using the Vectastain ABC kit (Vector). Peroxidase was subsequently revealed in a staining mixture containing 0.05\% 3,3'-diaminobenzidine hydrochloride (DAB, Sigma (Lyon, France)) and $0.03 \% \mathrm{H}_{2} \mathrm{O}_{2}$ in $0.05 \mathrm{M}$ TrisHCl pH 7.6.

\section{Competing interests}

The author(s) declare that they have no competing interests.

\section{Authors' contributions}

FC carried out the respiratory and oro-buccal behavior study of Hoxa2 null and Krox20 null mutant mice, started the anatomical study of Hoxa2 null mutants, participated in the conception and design of the study and drafted the manuscript. LJW and VM carried out the respiratory behavior of Krox20 hypomorph mutants. LJW and JC helped in the anatomical study of Hoxa2 null mice. MP and FMR generated the Hoxa2 EGFP(lox-neo-lox) and r2::Cre alleles, and performed the genotyping relative to these strains. MP and SD carried out the brain sectioning and EGFP staining of $\mathrm{r} 2$ specific Hoxa2-expressing cell progenies and FMR helped in the mutant analysis. ET and PC generated the two Krox20 alleles for the Krox20 null hypomorph mutant mice and did the genotyping relative to this strain. JC, FMR and PC conceived the study, and participated in its design and coordination and helped to draft the manuscript. All authors read and approved the final manuscript.

\section{Acknowledgements}

We thank L McKay for useful comments on the manuscript. We appreciate the kind gift of PHOX2A antibody by Drs JF Brunet and C Goridis. Work in JC's laboratory was funded by CNRS, Ministère de la Recherche et de la Technologie. Work in FMR's laboratory is supported by the Agence Nationale pour la Recherche (ANR), the Fondation pour la Recherche Medicale (FRM, 'Equipe Labelisée'), the Association pour la Recherche contre le Cancer (ARC), the Association Française contre les Myopathies (AFM), the Ministère pour le Recherche ( $\mathrm{ACl}$ program), and by institutional funds from CNRS and INSERM. Work in PC's laboratory was supported by 
the ARC, ARCEP, AFM and by institutional grants from INSERM and MENRT; ET was supported by a fellowship from the LNFCC.

\section{References}

I. Lumsden A, Krumlauf R: Patterning the vertebrate neuraxis. Science 1996, 274: I I09-III5.

2. Rijli FM, Gavalas A, Chambon P: Segmentation and specification in the branchial region of the head: the role of the Hox selector genes. Int J Dev Biol I998, 42:393-40I.

3. Sham MH, Vesque C, Nonchev S, Marshall H, Frain M, Gupta RD, Whiting J, Wilkinson D, Charnay $P$, Krumlauf R: The zinc finger gene Krox20 regulates HoxB2 (Hox2.8) during hindbrain segmentation. Cell 1993, 72:183-196.

4. Nonchev S, Vesque C, Maconochie M, Seitanidou T, ArizaMcNaughton L, Frain M, Marshall H, Sham MH, Krumlauf R, Charnay $\mathrm{P}$ : Segmental expression of $\mathrm{Hoxa-2}$ in the hindbrain is directly regulated by Krox20. Development 1996, I 22:543-554.

5. Tümpel S, Maconochie M, Wiedmann LM, Krumlauf R: Conservation and diversity in the cis-regulatory networks that integrate information controlling expression of Hoxa2 in hindbrain and cranial neural crest cells in vertebrates. Dev Biol 2002, 246:45-56.

6. Tümpel S, Cambronero F, Ferretti E, Blasi F, Wiedemann LM, Krumlauf R: Expression of Hoxa2 in rhombomere 4 is regulated by a conserved cross-regulatory mechanism dependent upon Hoxb I . Dev Biol 2007, 302:646-660.

7. Popperl H, Bienz M, Studer M, Chan SK, Aparicio S, Brenner S, Mann $\mathrm{RS}$, Krumlauf R: Segmental expression of Hoxb-I is controlled by a highly conserved autoregulatory loop dependent upon exd/pbx. Cell I995, 8I: I031-1042.

8. Maconochie M, Nonchev S, Morrison A, Krumlauf R: Paralogous Hox genes: function and regulation. Annu Rev Genet 1996, 30:529-556.

9. Tümpel S, Cambronero F, Wiedemann LM, Krumlauf R: Evolution of cis elements in the differential expression of two Hoxa2 coparalogous genes in pufferfish (Takifugu rubripes). Proc Natl Acad Sci USA 2006, 103:5419-5424.

10. Gavalas A, Davenne M, Lumsden A, Chambon P, Rijli FM: Role of Hoxa-2 in axon pathfinding and rostral hindbrain patterning. Development 1997, I24(19):3693-3702.

II. Davenne M, Maconochie MK, Neun R, Pattyn A, Chambon P, Krumlauf R, Rijli F: Hoxa2 and Hoxb2 control dorsoventral patterns of neuronal development in the rostral hindbrain. Neuron |999, 22:677-69|.

12. Pasqualetti M, Ren SY, Poulet M, LeMeur M, Dierich A, Rijli FM: A Hoxa2 knockin allele that expresses EGFP upon conditional Cre-mediated recombination. Genesis 2002, 32:I09-III.

13. Oury F, Murakami Y, Renaud JS, Pasqualetti M, Charnay P, Ren SY, Rijli FM: Hoxa2 - and rhombomere-dependent development of the mouse facial somatosensory map. Science 2006, 3 I3:|408-14|3.

14. Athanassiadis T, Olsson K, Kolta A, Westberg KG: Identification of c-Fos immunoreactive brainstem neurons activated during fictive mastication in the rabbit. Exp Brain Res 2005, 1 65:478-489.

15. Brocard F, Verdier D, Arsenault I, Lund JP, Kolta A: Emergence of intrinsic bursting in trigeminal sensory neurons parallels the acquisition of mastication in weanling rats. J Neurophysiol 2006, 96:2410-2424.

16. Lund JP, Kolta A, Westberg KG, Scott G: Brainstem mechanisms underlying feeding behaviors. Curr Opin Neurobiol 1998, 8:718-724.

17. Jacquin TD, Borday V, Schneider-Maunoury S, Topilko P, Ghilini G, Kato F, Charnay P, Champagnat J: Reorganization of pontine rhythmogenic neuronal networks in Krox20 knockout mice. Neuron 1996, 17:747-758.

18. Domínguez del Toro E, Borday V, Davenne M, Neun R, Rijli FM, Champagnat J: Generation of a novel functional neuronal circuit in Hoxal mutant mice. J Neurosci 200I, 2 I:5637-5642.

19. Smith JC, Ellenberger HH, Ballanyi K, Richter DW, Feldman JL: PreBotzinger complex: a brainstem region that may generate respiratory rhythm in mammals. Science I99I, 254:726-729.

20. Gray PA, Janczewski WA, Mellen N, McCrimmon DR, Feldman JL: Normal breathing requires preBotzinger complex neuroki-
nin-I receptor-expressing neurons. Nat Neurosci 200I, 4:927-930.

21. Borday C, Coutinho A, Germon I, Champagnat J, Fortin G: Pre-I post-otic rhombomeric interactions control the emergence of a fetal-like respiratory rhythm in the mouse embryo. J Neurobiol 2006, 66:1285-1301.

22. Thoby-Brisson M, Trinh JB, Champagnat J, Fortin G: Emergence of the pre-Bötzinger respiratory rhythm generator in the mouse embryo. J Neurosci 2005, 25:4307-4313.

23. Onimaru $\mathrm{H}$, Homma I: A novel functional neuron group for respiratory rhythm generation in the ventral medulla. J Neurosci 2003, 23:1478-|486.

24. Mellen NM, Janczewski WA, Bocchiaro CM, Feldman JL: Opioidinduced quantal slowing reveals dual networks for respiratory rhythm generation. Neuron 2003, 37:821-826.

25. Onimaru H, Homma I, Feldman JL, Janczewski WA: Point:Counterpoint: The parafacial respiratory group (pFRG)/pre-Bötzinger complex (preBötC) is the primary site of respiratory rhythm generation in the mammal. J Appl Physiol 2006, I 00:2094-2097.

26. Chatonnet F, Domínguez del Toro E, Thoby-Brisson M, Champagnat J, Fortin G, Rijli FM, Thaeron-Antono C: From hindbrain segmentation to breathing after birth: developmental patterning in rhombomeres 3 and 4. Mol Neurobiol 2003, 28:277-294.

27. Coutinho AP, Borday C, Gilthorpe J, Jungbluth S, Champagnat JA, Fortin G: Induction of a parafacial rhythm generator by rhombomere 3 in the chick embryo. J Neurosci 2004, 24:9383-9390.

28. McCrimmon DR, Milsom WK, Alheid GF: The rhombencephalon and breathing: a view from the pons. Respir Physiol Neurobiol 2004, I 43(2-3): 103-104.

29. Guimarães L, Domínguez-del-Toro E, Chatonnet F, Wrobel L, Pujades C, Monteiro LS, Champagnat J: Exposure to retinoic acid at the onset of hindbrain segmentation induces episodic breathing in mice. Eur J Neurosci 2007, 25( ( 2):3526-3536.

30. Taillebourg E, Buart S, Charnay P: Conditional, floxed allele of the Krox20 gene. Genesis 2002, 32: I I2-II3.

31. Karlberg P, Koch G: Respiratory studies in newborn infants. III. Development of mechanics of breathing during the first week of life. A longitudinal study. Acta Paediatr Suppl 1962, I35:| 2 I-I29.

32. Saunders RA, Milner AD: Pulmonary pressure/volume relationships during the last phase of delivery and the first postnatal breaths in human subjects. J Pediatr 1978, 93:667-673.

33. Fisher JT, Mortola JP, Smith JB, Fox GS, Weeks S: Respiration in newborns: development of the control of breathing. Am Rev Respir Dis 1982, I 25:650-657.

34. Mortola JP: Respiratory Physiology of Newborn Mammals Baltimore MD: John Hopkins University Press; 200I.

35. Giudicelli F, Taillebourg E, Charnay P, Gilardi-Hebenstreit P: Krox-20 patterns the hindbrain through both cell-autonomous and non cell-autonomous mechanisms. Genes Dev 200I, I 5:567-580.

36. Rijli FM, Mark M, Lakkaraju S, Dierich A, Dolle P, Chambon P: A homeotic transformation is generated in the rostral branchial region of the head by disruption of Hoxa: which acts as a selector gene. Cell 1993, 75:1333-1349.

37. Chatonnet F, Domínguez del Toro E, Voiculescu O, Charnay $P$, Champagnat J: Different respiratory control systems are affected in homozygous and heterozygous kreisler mutants. Eur J Neurosci 2002, 15:684-692.

38. Lumsden T: Observations on the respiratory centers in the cat. J Physiol (Lond) 1923, 57:53-160.

39. Bertrand F, Hugelin A: Respiratory synchronizing function of nucleus parabrachialis medialis: pneumotaxic mechanisms. J Neurophysiol 1971, 34:189-207.

40. Kobayashi S, Onimaru H, Inoue M, Inoue T, Sasa R: Localization and properties of respiratory neurons in the rostral pons of the newborn rat. Neuroscience 2005, 134:317-325.

4I. Potts JT, Rybak IA, Paton JF: Respiratory rhythm entrainment by somatic afferent stimulation. J Neurosci 2005, 25:1965-1978.

42. Bianchi AL, Denavit-Saubié M, Champagnat J: Central control of breathing in mammals: neuronal circuitry membrane properties and neurotransmitters. Physiol Rev 1995, 75: I-45.

43. Viemari JC, Bévengut $M$, Burnet $H$, Coulon $P$, Pequignot JM, Tiveron MC, Hilaire G: Phox2a gene A6 neurons and noradrenaline are 
essential for development of normal respiratory rhythm in mice. J Neurosci 2004, 24:928-937.

44. Chatonnet F, Boudinot E, Chatonnet A, Taysse L, Daulon S, Champagnat J, Foutz AS: Respiratory survival mechanisms in acetylcholinesterase knockout mouse. Eur J Neurosci 2003, I8:|4|9-1427.

45. Ren SY, Pasqualetti M, Dierich A, Le Meur M, Rijli FM: A Hoxa2 mutant conditional allele generated by Flp- and Cre-mediated recombination. Genesis 2002, 32:105-108.

46. Voiculescu O, Charnay P, Schneider-Maunoury S: Expression pattern of a Krox-20/Cre knock-in allele in the developing hindbrain, bones, and peripheral nervous system. Genesis 2000, 26: $123-126$

47. Helmbacher F, Pujades C, Desmarquet C, Frain M, Rijli FM, Chambon P, Charnay P: Hoxa-I and Krox-20 synergize to control the development of rhombomere 3. Development 1998, I 25:4739-4748.

48. Studer M, Lumsden A, Ariza-McNaughton L, Bradley A, Krumlauf R: Altered segmental identity and abnormal migration of motor neurons in mice lacking Hoxb-I. Nature 1996, 384:630-634.

Publish with Bio Med Central and every scientist can read your work free of charge

"BioMed Central will be the most significant development for disseminating the results of biomedical research in our lifetime. "

Sir Paul Nurse, Cancer Research UK

Your research papers will be:

- available free of charge to the entire biomedical community

- peer reviewed and published immediately upon acceptance

- cited in PubMed and archived on PubMed Central

- yours - you keep the copyright 